\title{
Entrepreneurs' Achieved Success: Developing a multi-faceted measure
}

Dominika Wach, Ute Stephan, Marjan Gorgievski, \& Jürgen Wegge

[author version of accepted manuscript, this version may deviate slightly from the publishers version]

please cite as:

Wach, D., Stephan, U., Gorgievski, M. \& Wegge, J. (2018). Entrepreneurs' achieved success: Developing a multi-faceted measure. International Entrepreneurship and Management Journal, DOI: 10.1007/s11365-018-0532-5

Corresponding author:

Dr. Dominika Wach

Department of Work and Organizational Psychology Institute of Work, Organizational and Social Psychology

TU Dresden

01062 Dresden, Germany

Dominika.wach@tu-dresden.de

Tel. 004917624746900

ORCID: 0000-0001-6344-9508

Prof. Ute Stephan

Aston University

Aston Business School

Aston Centre for Research into International Entrepreneurship and Business

Aston Triangle, Birmingham, B4 7ET

United Kingdom

U.Stephan@aston.ac.uk

ORCID: 0000-0003-4514-6057

Dr. Marjan Gorgievski

Erasmus University Rotterdam

Institute of Psychology

P.O. Box 1738, T13-03

3000 DR Rotterdam

The Netherlands

ORCID: 0000-0001-8939-0321

Prof. Dr. Jürgen Wegge

Department of Work and Organizational Psychology

Institute of Work, Organizational and Social Psychology

TU Dresden

01062 Dresden, Germany 
Entrepreneurs' Achieved Success: Developing a multi-faceted measure

\section{Abstract}

Firm performance is typically measured via objective financial indicators. However, researchers increasingly acknowledge that entrepreneurs do not measure their success solely in financial terms but that a range of often subjective indicators matter to them. This article contributes to the debate on entrepreneurial performance by studying how entrepreneurs assess their achieved success. Entrepreneurs' Achieved Success was conceptualized as a multi-faceted construct that includes entrepreneurs' self-reported achievement of firm performance, workplace relationships, personal fulfilment, community impact, and personal financial rewards. It was measured via the Subjective Entrepreneurial Success-Achievement Scale (SES-AS). Over the course of three studies $(N=390)$ the factorial structure of Entrepreneurs' Achieved Success was established and largely replicated in two cultures. Based on a nomological network, we documented relationships among Entrepreneurs' Achieved Success, quasi-objective indicators of firm performance, and entrepreneurs' financial satisfaction, creativity, and health. Based on our research, we propose a new conceptual framework to study performance in the context of entrepreneurship. This framework acknowledges both the success criteria that entrepreneurs wish to achieve and those that they actually achieve, and extends our understanding of firm performance.

\section{Keywords}

entrepreneur, achieved success, performance, measurement instrument, subjective assessment 


\section{Introduction}

Subjective entrepreneurial success, i.e., entrepreneurs' assessment of how well they perform measured against their own goals, has emerged as an area of interest among scholars seeking to better understand the behaviour of entrepreneurs (Cooper \& Artz, 1995; Gorgievski, Ascalon, \& Stephan, 2011). This interest is based on the observation that entrepreneurs' decisions cannot be explained solely by reference to economic firm performance indicators. Their actions are also driven by goals and values that go beyond economic returns (Fagenson, 1993; Gorgievski et al., 2011; Wach, Stephan, \& Gorgievski, 2016). For instance, entrepreneurs abandon successful firms when their own personal goals are not met (Bates, 2005). Conversely, entrepreneurs persevere with objectively underperforming firms if they are highly committed to the firm (DeTienne, Shepherd, \& De Castro, 2008). Such evidence suggests that entrepreneurs' subjective assessment of their success is important for the firm's future existence (Gimeno, Folta, Cooper, \& Woo, 1997; Reijonen \& Komppula, 2007). This raises the question of how entrepreneurs assess their own success, and how such assessments can be measured and integrated into organizational research on firm performance.

Entrepreneurship researchers typically define and measure entrepreneurial performance via firm-related outcomes such as survival (Reynolds, 1987), return on assets and sales, sales growth (Dess \& Robinson, 1984), growth in market share (Chandler \& Jansen, 1992), and the number of employees (Schutjens \& Wever, 2000). This economic approach to entrepreneurial success has received much criticism because subjective entrepreneurial success cannot be equated simply with firm performance (Sarasvathy, Menon, \& Kuechle, 2013).

The focus on firm-related performance indicators is in line with the economic view of entrepreneurs as being individuals who are rewarded with high monetary returns for bearing high levels of risk (Parker, 2009). Yet economic research increasingly acknowledges that 
entrepreneurs may seek different types of utility, such as independence and satisfaction, over and above monetary returns (Van Praag \& Versloot, 2007; Walker \& Brown, 2004). Psychologically-based approaches argue that, just as for other individuals, entrepreneurs are likely to pursue a range of different goals through their work, and will consequently judge their performance against these goals, which become their success criteria (Wach et al., 2016). Self-actualization, independence, autonomy, enhanced status, and social contribution (Seelos \& Mair, 2005; Stephan, Hart, \& Drews, 2015), and personal learning, fulfilment, and work-life balance (Jayawarna, Rouse, \& Kitching, 2011) are some possible examples of entrepreneurs' success criteria proposed in the literature.

There is some evidence that entrepreneurs value and strive for multiple success criteria simultaneously. For instance, Gorgievski et al. (2011) identified the person-oriented and business-oriented dimensions that underlie entrepreneurs' perceptions of their success. Similarly, Fisher, Maritz, and Lobo (2014) introduced several personal and business performance criteria to capture subjective entrepreneurial success. Recently, Wach et al. (2016) showed that entrepreneurs define their success by measures that go beyond financial rewards but also incorporate workplace relationships, the level of personal fulfilment, and community impact. While this research offers a useful starting point by highlighting the fact that entrepreneurs value multiple success criteria simultaneously, research is still lacking as to how entrepreneurs assess their success; particularly concerning the criteria they use to determine whether they have achieved 'success' and how these criteria are structured (i.e. how they relate to each other).

To address this important question, we define entrepreneurs' assessment of success in terms of goal achievement. According to Schulz and Heckhausen (1996), goal achievement is a subjective and individualized concept referring to the "realization of desired outcomes and the avoidance of undesired outcomes" (p. 704). As values are motivational goals that guide 
attitudes and behaviours (Fischer \& Boer, 2016), one may argue that the success criteria valued by entrepreneurs are equivalent to those they use in assessing their actual achievements. However, as discussed in more detail below, empirical evidence suggests that the link between values and behaviours can be complex. The extent to which values are expressed in behaviours depends on the type of value being considered, as well as other contextual factors such as economic resources (Fischer, 2006). Thus, even though prior research offers insights on valued success criteria, it is not clear whether entrepreneurs measure their achievements against the same metrics.

This is where our study aims to advance research on entrepreneurial performance. First, we introduce the concept of 'entrepreneurs' achieved success' which - to our knowledge - has not yet been systematically studied. We also develop a new diagnostic tool that measures Entrepreneurs' Achieved Success. Second, we explore the underlying structure and test the cross-cultural equivalence of Entrepreneurs' Achieved Success. A third goal of our research is to provide evidence for the construct validity of the new scale, thereby addressing the association between valued and actual achieved success criteria, and their conceptual distinctiveness.

\section{Theoretical background}

Within entrepreneurship research, performance has been conceptualized and measured in different ways, whether it is across broad categories, or via subjective measures of entrepreneurs' satisfaction with their performance, or by measuring firm performance in relation to that of competitors (Chandler \& Hanks, 1993). Broad categories are anchored to objective success indicators, and typically include entrepreneurs' earnings, firm sales, return on investment (ROI), cash flow, market share, as well as changes in these parameters. In contrast, subjective measures of entrepreneurs' satisfaction refer to entrepreneurs' self- 
reported overall evaluation of how well their firms are performing and their degree of satisfaction with this performance (Chandler \& Hanks, 1993). Alternatively, entrepreneurs are asked to compare the performance of their firm to that of a rival (Lumpkin \& Dess, 2001; Powell \& Eddleston, 2008), or to the performances of leading firms in their market (Gupta \& Govindarajan, 1986).

It is our contention that firm-related performance is not the only criterion against which entrepreneurs assess their success. Past research on entrepreneurial motives and goals collectively suggests that entrepreneurs view success broadly; they value aspects that go far beyond firm performance and monetary rewards. Entrepreneurs have been found, for example, to attach importance to autonomy and independence (Curtin \& Reynolds, 2008; Jayawarna et al., 2011), self-realization and personal development (Benzing \& Chu, 2009; Jayawarna et al., 2011), achievement (Curtin \& Reynolds, 2008; Edelman, Brush, Manolova, \& Greene, 2010), monetary incentives, status and social recognition (Benzing \& Chu, 2009), personal and family security (Kuratko, Hornsby, \& Naffziger, 1997; Robichaud, McGraw, \& Roger, 2001), relationships with employees and stakeholders (Gorgievski et al., 2011; Jayawarna et al., 2011), creating social value and helping others (Lukes \& Stephan, 2012; Stephan et al., 2015), and spirituality (Kauanui, Thomas, Rubens, \& Sherman, 2010).

Several studies have investigated the underlying structure of the success criteria that are valued by entrepreneurs. For instance, Orser and Dyke (2009) extracted four underlying facets to capture success criteria relevant for entrepreneurs: market acceptance; professional autonomy; work-life balance; and financial indicators. Their conceptualization differs from that of Gorgievski et al. (2011) who proposed a two-dimensional model of valued success criteria, including dimensions that were person-oriented (e.g., personal satisfaction) and business-oriented (e.g., profitability, innovation). They found that entrepreneurs perceived themselves to be successful if they achieved personal targets (e.g., satisfaction with life and 
business) and business performance objectives (e.g., a continually growing business). Wach et al. (2016) found evidence for a more comprehensive, five-dimensional conceptualization of entrepreneurial success composed of firm performance, workplace relationships, personal fulfilment, community impact, and personal financial rewards. Recently, Staniewski and Awruk (2017) have developed a Questionnaire of Entrepreneurial Success (QES), which differentiates subjective and objective short- and long-term success perspectives.

Past research on entrepreneurs' motives and goals, as well as research on the importance attached to different success criteria, offers an important starting point for the current research. However, none of these prior studies focused explicitly on entrepreneurs' subjective assessment of their achieved success. This is problematic, because the value that entrepreneurs attach to multiple success criteria differs conceptually from how entrepreneurs assess the success that they have actually achieved. While the first concept refers to entrepreneurs' internal representations of desired outcomes, the latter captures the actual attainment of those standards through behaviours (i.e. goal achievement). We know from extant research on the (in)congruence of values with expression in attitudes and behaviours (Fischer \& Boer, 2016) that the link between valued and actually achieved success criteria can be quite complex. Whether values find their expression in behaviour varies depending on the economic, ecological and institutional contexts; for instance, in resource-rich environments or environments with strong societal norms, values are more likely to guide behaviours (Fischer, 2006; Fischer \& Boer, 2016). Furthermore, diminishing marginal utility (Maseland \& van Hoorn, 2009) explicates that the value assigned to the realization of a given goal decreases with satiation (the growing achievement of this goal). Diminishing marginal utility helps to explain why Wach et al. (2016) found that entrepreneurs highly valued monetary rewards when they earned low incomes and were dissatisfied with their financial situation. 
The aim of this research is to provide a new conceptualization and measurement instrument of Entrepreneurs' Achieved Success to fill the research gap delineated above. In Study 1 we intend to establish that Entrepreneurs' Achieved Success consists of five separate facets (indicators) that are similar to the facets of desired success valued by entrepreneurs as established by Wach et al. (2016). These five facets are firm performance, workplace relationships, personal fulfilment, community impact, and personal financial rewards. Study 2 then seeks to provide a cross-cultural replication of the five-facet conceptualization of Entrepreneurs' Achieved Success. In Study 3, we establish a nomological network of relationships between the five facets of success and other constructs, such as matching economic measures of firm performance, entrepreneurs' creativity, and health. We also establish novel evidence on the relationships between the success criteria that entrepreneurs value and desire, and those that they feel they achieve. Based on prior research on valued and achieved goals (reviewed above), it is unclear how these concepts may overlap. Our approach allows us to validate the five facets of Entrepreneurs' Achieved Success and the instrument developed for their measurement, i.e. the Subjective Entrepreneurial SuccessAchievement Scale (SES-AS). In the following section, we derive the specific hypotheses that are tested in the three studies. We then report the results of the three studies and conclude with an overall discussion.

\section{Overview of Study 1: The factorial structure of Entrepreneurs' Achieved}

\section{Success}

To conceptualize and measure Entrepreneurs' Achieved Success we build on the work of Wach, Stephan, and Gorgievski (2016) who developed and validated the 'Subjective Entrepreneurial Success-Importance Scale' (SES-IS), capturing five separate success criteria that are valued by entrepreneurs. Thus, our research suggests that separate aspects of 
performance exist, as opposed to one abstract and generalized factor of success. Such a multi-faceted view of Entrepreneurs' Achieved Success follows the recommendation of Miller, Washburn, and Glick (2013) to adapt a so-called 'separate constructs approach'. This approach reflects not only in our theoretical conceptualization but also in our development of a new diagnostic tool to measure Entrepreneurs' Achieved Success across multiple separate indicators. In doing so, we aim to overcome the mismatch between theory development and measurement of success. That is to say, in the literature to date, there is recognition of a variety of indicators that capture diverse aspects of firm performance, but there is no consistent conceptualization of firm performance (Miller et al., 2013). Our use of the 'separate constructs approach' in developing a theory and measuring success challenges the current research tradition that typically conceptualizes performance as a single global factor while only sparsely measuring narrower success indicators (Miller, Washburn, \& Glick, 2013).

The first facet of success, firm performance, includes firm profitability, turnover and sales, as well as growth in profit and increased market share. These success criteria have been frequently utilised in entrepreneurship research and have even been equated with entrepreneurial success (Gorgievski et al., 2011; Lumpkin \& Dess, 2001; Sydler, Haefliger, \& Pruksa, 2014). The second facet, workplace relationships, refers to relationships with customers and employees as well as to employee satisfaction (Harter, Schmidt, \& Hayes, 2002; Payne \& Joyner, 2006; Wach et al., 2016). The third facet of success, personal fulfilment, is composed of work-life balance (Eddleston \& Powell, 2012), work flexibility (Vandello, Hettinger, Bosson, \& Siddiqi, 2013), own decision making (Busenitz \& Barney, 1997; Gorgievski et al., 2011), and personal development (St-Jean \& Audet, 2012). These apparently diverse criteria belong together since they all represent interdependent nonpecuniary benefits. It is likely that an entrepreneur who has high decision-making authority 
manages his or her time more flexibly, which in turn increases work-life balance and provides opportunities for further personal development. The fourth facet of success, community impact, is associated with contributing to society (Brammer, Millington, \& Rayton, 2007), managing an environmentally sustainable company (York \& Venkataraman, 2010) and taking care of employees (Payne \& Joyner, 2006; Wach et al., 2016). Lastly, the fifth facet, personal financial rewards, includes personal income growth (Gorgievski et al., 2011; Harada, 2003), experiencing financial security (Kuratko et al., 1997), and enjoying an abundance of disposable income (Cassar, 2007). We formulated the following hypothesis:

Hypothesis 1 (H1). Entrepreneurs' Achieved Success (as measured via the SES-AS) consists of five facets: firm performance, workplace relationships, personal fulfilment, community impact, and personal financial rewards that demonstrate sufficient factorial validity and reliability.

\section{Overview of Study 2: Cross-cultural replication of the Entrepreneurs'}

\section{Achieved Success}

Cross-cultural studies of entrepreneurial success are scarce. Thus, our research aims to provide evidence for the cross-cultural replicability of our five-facet conceptualization of Entrepreneurs' Achieved Success using samples of German and Polish entrepreneurs. We selected these countries because there are considerable differences between Germany and Poland in terms of cultural practices.

According to the GLOBE study (House, Hanges, Javidan, Dorfman, \& Gupta, 2004), Germans exhibit higher assertiveness (4.77 in East Germany, 4.66 in West Germany versus 4.11 in Poland) and performance orientation than do Poles (4.16, 4.42 versus 3.96) (Brodbeck, Frese, \& Javidan, 2002). High degrees of assertiveness and performance orientation are cultural practices that align with the firm performance and personal financial 
rewards facets of Entrepreneurs' Achieved Success. Poles on the other hand score considerably higher on institutional and in-group collectivism than do individuals from former East and West Germany (4.51 versus 3.67, 3.97 for institutional and 5.55 versus 4.59, 4.16 for in-group collectivism), and these are cultural practices that align with the workplace relationships facet of success. Conversely, individualism aligns with the personal fulfilment facet and is higher in Germany than in Poland while gender egalitarianism and humane orientation can be seen to align with the community impact facet of success, and are less pronounced in former East and West Germany as compared to Poland (3.17, 3.25 versus 3.94 for gender egalitarianism and 3.45, 3.30 versus 3.67 for humane orientation). Such differences in cultural practices between Germany and Poland suggest that we can meaningfully test the cross-cultural robustness of the five-facet conceptualization of Entrepreneurs' Achieved Success in these two countries. Existing cultural differences may influence the level of achieved success but should not impact the underlying structure of the concept of Entrepreneurs' Achieved Success. Therefore, we propose:

Hypothesis 2 (H2). The underlying structure of Entrepreneurs' Achieved Success (as measured via the SES-AS) can be replicated in an independent Polish sample.

\section{Overview of Study 3: Criterion validity of the Entrepreneurs' Achieved}

\section{Success in German and Polish samples}

In exploring the criterion validity of Entrepreneurs' Achieved Success, we draw upon the recommendation of Miller et al. (2013), who proposed developing the nomological network to indicate how various components of performance relate both to each another and to different outcomes. We thus look at the relationships between the five separate facets of Entrepreneurs' Achieved Success and with other conceptually related variables. We expect 
the achievement of facets firm performance and personal financial rewards to be positively associated with the broad-categories indicators of firm performance that are typically utilized in entrepreneurship research (Chandler \& Hanks, 1993). These indicators are firm pre-tax profit, firm net profit, firm revenue development, firm employee growth, and entrepreneur's annual income. We also include entrepreneurs' satisfaction with their financial situation and their evaluation of global firm financial success because such self-ratings frequently have been utilized in past research. For instance, in their meta-analysis Rauch and Frese (2007) relate personal characteristics to such measures of entrepreneurial success. In a similar vein, Powell and Eddleston (2008) collected information on satisfaction (i.e. satisfaction with earning a lot of money, growing a world-class business, and leading a large rapidly growing enterprise) to capture success. We formulated the following hypotheses:

Hypothesis 3 (H3). Entrepreneurs' achievement (as measured via the SES-AS) of firm performance relates positively to firm pre-tax profit, firm net profit, firm revenue development, and firm employee growth as well as to self-reported global firm financial success.

Hypothesis 4 (H4). Entrepreneurs' achievement (as measured via the SES-AS) of their personal financial rewards relates positively to their self-reported annual income and satisfaction with financial situation.

According to Fisher et al. (2014), entrepreneurs perceive themselves as successful when they are satisfied with their life and business. In addition, Gorgievski et al. (2011) found personal satisfaction to be the most highly valued success criterion for entrepreneurs, followed by profitability, and satisfied stakeholders. Based on the logic that for entrepreneurs their achievement of firm and personal success criteria is a proxy of a successful career, we expect all facets of achieved success to relate positively to self-reported career success. Thus, we formulated the following hypothesis: 
Hypothesis 5 (H5). Entrepreneurs' achievement (as measured via the SES-AS) of success relates positively to their self-reported career success.

Creativity is an "(...) ability to produce work that is both novel (i.e. original, unexpected) and appropriate (i.e. useful, adaptive concerning task constraints)" (Sternberg \& Lubart, 1999) (p. 3). Creativity is seen as an essential part of the entrepreneurial toolbox (Rauch \& Frese, 2007) and is positively related to firm performance and venture growth (Gielnik, Frese, Graf, \& Kampschulte, 2012). By reason of the link between creativity and business growth, it is also suggested that creativity positively affects communities and society in general (Bilton, 2007). Some work suggests that entrepreneurs who seek positive community, social, and environmental impacts are particularly creative (Renko, 2013). Thus, we formulated following hypothesis:

Hypothesis 6 (H6). Entrepreneurs' achieved (as measured via the SES-AS) firm performance and community impact relate positively to entrepreneurs' self-reported creativity.

Achieved success may also link with entrepreneurs' health. Entrepreneurs invest significant amounts of energy, time, and money to sustain their firms. Thus, success may boost their health and well-being, while setbacks in the business are likely to negatively impact their health and well-being. There is evidence to corroborate this. For instance, more successful entrepreneurs were found to be healthier (Rau et al., 2008), and those experiencing work-related strain assessed themselves as less personally and financially successful (Dijkhuizen, Gorgievski, van Veldhoven, \& Schalk, 2014). Equally, entrepreneurs feel stressed when they experience financial problems or when they struggle to achieve their desired level of firm performance (i.e. growth, sales turnover, profit) (Grant \& Ferris, 2012). We therefore formulated the following hypothesis:

Hypothesis 7 (H7). Entrepreneurs' achievement (as measured via the SES-AS) of firm 
performance, personal financial rewards, and personal fulfilment relates positively to entrepreneurs' health.

To our knowledge, no research exists on the relationship between entrepreneurs' valued and actual achieved success criteria. A better understanding of this relationship can help to shed a light both on entrepreneurial performance and on persistence in entrepreneurship, such as when entrepreneurs withdraw from firms that perform well (Bates, 2005). It provides insight as to whether a positive link between desired and achieved entrepreneurial outcomes exists, and whether such a link applies to all facets of success. This knowledge can also increase our understanding of entrepreneurs' strategic decision-making and their well-being. We formulated the following exploratory research question:

Research Question 1. How do the valued and achieved facets of success i.e. firm performance, workplace relationships, personal fulfilment, community impact, and personal financial rewards, relate to each other?

\section{Research method}

As we conducted three studies in two countries, we will start with descriptions of all three samples, followed by a brief description of the measures used.

\section{German Sample 1 (used for testing H1 and to answer Research Question 1)}

In 2008 we recruited 184 entrepreneurs who were owner-managers of small and medium sized private firms employing a maximum of 300 employees. We sampled entrepreneurs via social networks and online platforms such as Xing, LinkedIn, AIESEC, entrepreneurs' associations, and chambers of commerce. We also randomly selected every $20^{\text {th }}$ entry in each of the 16 German states using Yellow Pages (Dillman, 2000). Participation was voluntary and anonymous. Participation rate was 11.55 percent.

Entrepreneurs filled out either an online (50 percent of participants, $n=92$ ) or a paper and pencil questionnaire. Women participated significantly more frequently in the online 
survey than men $\left(\chi^{2}=27.57, d f=1, p<.001\right)$. The mean values of the five facets of Entrepreneurs' Achieved Success measured via the SES-AS measurement instrument did not differ significantly between the two modes of data collection (Pillai-Spur test was at $p=.26$ n.s.). We excluded five participants with missing data, thus the total Sample 1 consisted of 179 entrepreneurs who were on average 45.78 years old $(S D=9.72$, ranging from 22 to 72 , $M d n=45)$ and were self-employed for an average of 12.69 years $(S D=7.70$, ranging from 0 to $38, M d n=11.29$ ). Only two entrepreneurs had been self-employed for less than one year. Women represented 26.60 percent $(n=44)$ of the whole sample. About 58 percent $(n=102)$ of the participants held a university degree and 63 percent $(n=115)$ of the entrepreneurs were firm founders. On average, firms were 24 years old $(S D=30.72$, ranging from 0 to 182 , $M d n=14)$. Only two firms had operated on the market for less than one year, while 16 firms operated for more than 60 years. Entrepreneurs hired 22.37 employees $(S D=43.68$, ranging from 1 to $300, M d n=10$ ), of which two firms employed only one person and two firms employed 300 employees. Firms operated in building and construction (42.5 percent, $n=76$ ), innovative technologies and electronics (18.4 percent, $n=33)$, services (26.3 percent, $n=$ 47 ), and trading (12.8 percent, $n=23)$.

\section{German Sample 2 (used for testing H1 to H6)}

We collected further data in 2012. Entrepreneurs who were owner-managers were sampled via social networks and online platforms, entrepreneurs' associations, and chambers of commerce. Response rate was 33.13 percent. All participants filled out an online questionnaire. In total we sampled 115 entrepreneurs; however, we excluded five participants due to missing data. Entrepreneurs were on average 47.37 years old $(S D=9.68$, ranging from 27 to 74 years, $M d n=48), 82.10$ percent $(n=87)$ were men, 39.10 percent held a university degree $(n=43)$ and 64.80 percent $(n=70)$ were firm founders. On average, the firms had operated on the market for 27.30 years $(\mathrm{SD}=29.00$, ranging from 1 year to 203 years, $M d n=$ 
20). Sixteen firms had existed for more than 60 years. Entrepreneurs employed 17.89 employees $(S D=40.24$, ranging from 0 to $300, M d n=7)$; five firms had no employees and one firm more than 250 employees. They operated in building and construction (13.60 percent, $n=15)$, trading (4.50 percent, $n=5)$, services (20.90 percent, $n=23)$, manufacturing (48.2 percent, $n=53)$, gastronomy (4.5 percent, $n=5)$, automobile $(2.70$ percent, $n=3)$, medicine ( 0.90 percent, $n=1)$, and production (4.50 percent, $n=5)$.

\section{Polish Sample (used for testing H1, H2, H7, and Research Question 1)}

In 2009, we collected data in Poland. Participants were recruited via telephone; the response rate was 20 percent. Entrepreneurs filled out either an online or paper and pencil questionnaire (53 percent online, $n=59$ ). We did not find significant differences in mean values with regards to the five success facets (Pillai-Spur, $F=1.45, d f=5, p=.129 \mathrm{~ns}$ ) nor with regards to socio-demographic variables, which demonstrates that the results were not affected by the method of data collection. The Polish sample consisted of 101 respondents who completed the survey. Entrepreneurs were on average 38 years old $(S D=10.68$, ranging from 22 to $72, M d n=35$ years), married (63 percent, $n=66$ ), and about 67 percent of them $(n=68)$ had a university degree. Men made up 53.5 percent $(n=54)$ of the sample. All respondents were founders of the firms that they currently owned and managed. They employed on average 9 employees $(S D=20.28$, ranging from 0 to $180, M d n=3.5$ employees). Twenty firms had no employees. Firms had operated at least one year on the market in the following industrial sectors: building and construction ( 4 percent, $n=4)$, innovative technologies and electronics (22 percent, $n=22$ ), services (67 percent, $n=67$ ), trading $(4, n=4)$, and transportation (4 percent, $n=4)$. 


\section{Measures}

Entrepreneurs' Achieved Success was measured via the Subjective Entrepreneurial SuccessAchievement Scale (SES-AS). We asked participants to indicate how successful they had been in the past year in achieving 17 specific success criteria representing the five separate facets of success. These were firm performance ( 4 items), workplace relationships (3 items), personal fulfilment (4 items), community impact (3 items), and personal financial rewards (3 items) (see Appendix 1, left row). The answering format ranged from 1 'not achieved at all' to 5 'absolutely achieved'. A sample item was 'In the past year I achieved work-lifebalance...' All items are adapted from the SES-IS scale (Wach et al., 2016), although we changed the instruction to assess entrepreneurs' actual achievement of success criteria instead of the value entrepreneurs attach to these criteria. The German version of SES-AS scale was translated into Polish by a bilingual researcher and translated back again by an independent researcher.

To answer Research Question 1, we assessed entrepreneurs' valued success criteria using the Subjective Entrepreneurial Success-Importance Scale (SES-IS) (Wach et al., 2016). Entrepreneurs reported the importance to them of the following five facets of success: firm performance (4 items), workplace relationships (3 items), personal fulfilment (4 items), community impact (3 items), and personal financial rewards (3 items), using a 5-point Likert scale going from 1 'not important at all' to 5 'absolutely important'. 
Firm-related performance indicators. We collected entrepreneurs' reports on their firm pre-tax profit and firm net profit in the years 2009, 2010 and 2011. We also asked entrepreneurs to report their firm revenue development in the years 2008 to 2009, 2009 to 2010, and 2010 to 2011, as well as employee growth over the last year, and their own annual income. We log-transformed theses variables to obtain a normal distribution.

Entrepreneurs' satisfaction with their financial situation was measured using two items from the German Federal Health Survey (Bellach, Knopf, \& Thefeld, 1998) that tackled satisfaction with one's personal income and with one's own financial situation. The response format was a 7-point scale using Kunin-Faces (Kunin, 1955), ranging from 1 'very sad, unsatisfied' to 7 'very happy'. A sample item was 'How satisfied are you with your income?' Cronbach's Alpha was $\alpha=.93$.

We collected entrepreneurs' self-reports on global firm financial success using a single item: 'In general, my firm is financially very successful'. The response format was a 5-point Likert scale ranging from 1 'absolutely disagree' to 5 'absolutely agree'.

Entrepreneurs' self-reported career success was measured with the 6-item career success subscale derived from an instrument measuring individual stress management and coping pattern styles (Schaarschmidt \& Fischer, 2001). High scores reflect a positive evaluation of one's career and occupational accomplishments. The response format ranged from 1 'applies absolutely' to 5 'does not apply at all'. A sample item was 'My present professional life is fairly successful'. Cronbach's Alpha was $\alpha=.89$.

Entrepreneurs' creativity was measured with 7 items based on the scale introduced by Zhou and George (2001) and refined by Baer and Oldham (2006), with a 7-point response format ranging from 1 'does not apply at all' to 7 'applies absolutely'. Cronbach's Alpha was $\alpha=.89$. A sample item was 'I often have new and innovative ideas'. 
Entrepreneurs' mental health was measured with the 7 items of the SF-12 Health Survey (Bullinger \& Kirchberger, 1998), which includes areas such as social functioning, role limitations due to emotional problems, and mental health, as well as enquiries about the subject's positive and negative emotional states. A sample item was 'During the past four weeks, how much of the time have your emotional problems interfered with your social activities (like visiting friends, relatives)?' Cronbach's Alpha reliability coefficient was $\alpha=$ .78 .

We also measured entrepreneurs' vital exhaustion using the shortened Maastricht Exhaustion Questionnaire (9 items) (Kopp, Falger, Appels, \& Szedmak, 1998), which is widely used in clinical and healthy samples (Appels \& Mulder, 1988). The scale assessed fatigue, trouble falling asleep, waking up at night, general malaise, apathy, irritability, loss of energy, demoralization, and waking up exhausted. Answers were scored as 0 for 'no', 1 for 'indeterminate', and 2 for 'yes'. The total score ranged from 0 to 18 , with a score between 0 and 2 indicating not exhausted, a score between 3 and 10 suggesting moderate exhaustion, and a score above 11 indicating severe (i.e. clinical) exhaustion. Cronbach's Alpha reliability coefficient was $\alpha=.83$. A sample item was 'Do you often feel tired?'

Socio-demographics. We collected information on gender, age in years, nationality, industry sector, firm age, and number of employees currently and one year ago.

\section{Results}

\section{Study 1: The factorial structure of Entrepreneurs' Achieved Success (SES-AS)}

In all three samples we tested H1, stating that Entrepreneurs' Achieved Success is composed of five facets, including firm performance, workplace relationships, personal fulfilment, community impact, and personal financial rewards that demonstrate sufficient factorial validity and reliability. 


\section{German Sample 1}

The 17 items were normally distributed (kurtosis and skewness ranged between -1.10 and .67). To test the fit of the data to the five-facet model as indicated in H1, we conducted a confirmatory factor analysis (CFA) using AMOS (Arbuckle, 2014) (maximum likelihood estimation). The hypothesized model (M1, Table 1$)$ fitted the data fairly well $(C F I=.896$, REMSEA $\left.=.072, d f=109, \chi^{2}=209.835\right)$. Based on the examination of modification indices, we allowed 4 error terms to correlate, and the model fit increased significantly $(C F I=.919$, REMSEA $=.068$ and $d f=106, \chi^{2}=192.720$, M1.1, Table 1). We also tested an alternative model M2 in which all items loaded on one single latent factor Entrepreneurs' Achieved Success, and an alternative model M3 in which five success facets loaded on one second order factor Entrepreneurs' Achieved Success. Neither M2 nor M3 fitted the data better than the revised model M1.1 (Table 1).

Further, in line with H1, we examined internal consistency reliability as well as convergent and discriminant validity of the SES-AS (Table 2). Cronbach's Alpha reliabilities $(\alpha)$ were above .70 for three facets (i.e. subscales) but .53 for community impact and .65 for personal fulfilment. Composite reliability (CR) exceeded the recommended threshold of .60 (Bagozzi \& Yi, 1988) for four out of five facets (except community impact), suggesting good internal consistency. All item factor loadings were well above the recommended .40 threshold, except for the item 'environmentally friendly firm'. The average variance extracted (AVE) was below the recommended .50 threshold (Fornell \& Larcker, 1981) for the facets workplace relationships, personal fulfilment and community impact. However, CR was higher than AVE with regards to all five facets, supporting convergent validity of SES-AS (Hair, Hult, Ringle, $\&$ Sarstedt, 2016). With regard to discriminant validity, the findings were ambiguous. On the one hand, maximum shared variance (MSV) was higher than AVE for all five facets. On the other hand, the average shared squared variance (ASV) was lower than AVE for four out of 
five facets (it was not the case for community impact), supporting their discriminant validity (Hair, Black, Babin, Anderson, \& Tatham, 2006). Although the reliability of facet community impact was rather low, in general $\mathrm{H} 1$ has been confirmed.

\section{German Sample 2}

Next, we aimed to cross-validate the SES-AS scale in the second independent German Sample 2. To increase the Cronbach's Alpha reliability of specific subscales we included additional items, i.e. item 'maintenance of private contacts' into the facet personal fulfilment, item 'social recognition' into facet community impact, as well as items 'strong relationships with employees' and 'employee loyalty' into the facet workplace relationships. Those items were derived from the qualitative Study 1 conducted by Wach et al. (2016).

All 21 items were normally distributed, with the kurtosis of item 'strong employee relationships' being slightly over the recommended threshold (2.26). We conducted CFA with the extended revised model and obtained moderate model fit (M1.2, Table 1). Based on modification indices, we deleted four items: 'firm profitability', 'strong customer relationships', 'work-life balance', and 'maintenance of private contacts'. We also moved the item 'social responsibility for employees' from facet community impact to facet workplace relationships. We believe this is theoretically defensible based on the content of the item which references the 'inside' of the company, i.e., caring for employees rather than the 'outside' of the company as in the facet community impact. . This way, we obtained a very good fit of the final five-facet model with no error terms being correlated (M.1.3, Table 1, German sample 2). This model is the basis for further analyses. The revised SES-AS structure with 17 items is presented in Figure 1. Cronbach's Alpha of the revised SES-AS ranged between .60 and .91 . The CR exceeded the recommended threshold of .60 and is higher than the AVE (Table 2 for German sample 2). All item factor loadings were well above the recommended .40 threshold, except for the item 'personal work flexibility'. 
Overall, the results suggest that convergent validity of the SES-AS facets was supported. The AVE was above the recommended .50 threshold, with the exception of the facet personal fulfilment. The MSV was lower than AVE, except for the facet firm performance. The ASV was lower than AVE for all five facets. In sum, the convergent and discriminant validity of the SES-AS improved significantly in this study, supporting H1. All scale development steps are presented in Appendix 1.

\section{Polish Sample}

In the Polish Sample, all items of the revised version of SES-AS were normally distributed except for the item 'strong customer relationships'. The underlying five-facet structure of SES-AS fitted well to the Polish data (CFI was .987, REMSEA was .031, $d f=109, \chi^{2}=119$. 473) (M.1.3, Table 1, Polish sample 3). Cronbach's Alpha ranged between .67 and .88, CR exceeded the recommended threshold of .60, and CR was higher than AVE, which suggests that convergent validity of SES-AS was supported. The AVE was below the recommended .50 threshold for the facets personal fulfilment and community impact. The MSV and ASV were lower than AVE for all five facets. All item factor loadings were well above the recommended .40 threshold; we thus conclude that the evidence largely supported the discriminant validity of the SES-AS (Table 2).

In conclusion H1 received support across three different samples: Entrepreneurs' Achieved Success consists of five facets, similar to the facets that have been established for 'Entrepreneurs' Valued Success'.

\section{Please insert Table 1 and 2 about here}

\section{Study 2: Cross-cultural replication of the Entrepreneurs' Achieved Success}

To test H2, on cross-cultural robustness of the Entrepreneurs' Achieved Success operationalisation, we investigated equivalence (i.e. invariance) of the five-facet solution of the SES-AS instrument in German sample 2 and the Polish sample. In the first step we tested 
configural invariance to see whether the underlying model of Entrepreneurs' Achieved Success fitted well across samples. The results revealed that the configural model (unconstrained model) fitted the data well (M1, Table 3; CFI $=.967, R M S E A=.037, \chi^{2}=$ 279.393, $d f=218, p<.001)$.

In the second step we tested factor loadings invariance, which assumes that Polish and German entrepreneurs respond to the items in the same way. In other words, we tested if the strength of the factor loadings was the same across cultures. This model was tested by constraining all factor loadings to be the same across the two samples. The model fit deteriorated significantly as indicated by the chi ${ }^{2}$ test $\left(\chi^{2}\right)$ and delta $C F I(\triangle C F I)(\mathrm{M} 2$, Table 3). To determine the source of the lack of invariance we tested the factor loading invariance of the five facets separately, comparing them with configural model M1. We found evidence for full invariance of the factor loadings for the facets firm performance (M2.1), personal financial rewards (M2.5), and workplace relationships (M2.2) as well as partial invariance of the factor loadings for facet community impact (M2.4), where the item 'environmentally friendly firm' was not culturally invariant. Only the facet personal fulfilment (M2.3) showed no cross-cultural invariance (Table 3, Figure 1). Notably, factor loading invariance is an important assumption only when testing for mean differences across groups (Byrne, Shavelson, \& Muthen, 1989), which was not a focus in the current study.

Please insert Table 3 and Figure 1 about here

\section{Study 3: Criterion validity of Entrepreneurs' Achieved Success}

The criterion validity of the SES-AS was tested in German Sample 2 and the Polish Sample (H3 - H7). H3 proposed that entrepreneurs' achievement of firm performance, i.e. the mean value of that facet of SES-AS, will relate positively to firm pre-tax profit, firm net profit, firm revenue development, and firm employee growth as reported by entrepreneurs. We 
largely support this hypothesis as we found overall positive correlations (ranging from $r=$ $.12, p<.05$ to $r=.41, p<.01)$ between the SES-AS facet firm performance and firm-related quasi-objective success indicators in German Sample 2. In line with H3 we found the facet firm performance related positively to global firm financial success in both samples (German Sample 2: $r=.60, p<.01$, Table 5; Polish Sample: $r=.59, p<.01$, Table 6). As proposed in $\mathrm{H} 4$, the facet personal financial rewards correlated positively with entrepreneurs' annual income $(r=.41, p<.01)$ and entrepreneurs' satisfaction with their financial situation $(r=.68$, $p<.01)$ (Table 5).

\section{Please insert Table 4 around here}

Supporting H5, we found that entrepreneurs' self-reported career success linked positively to all five facets of achieved success, ranging from $r=.30$ to $r=.47(p<.01)$. In line with H6, facets firm performance $(r=.29, p<.01)$ and community impact $(r=.24, \mathrm{p}<$ $.05)$ were positively associated with entrepreneurs' self-reported creativity (Table 5).

\section{Please insert Table 5 about here}

With regards to relationships between entrepreneurs' achieved success and their health in the Polish Sample (H7), we found the facets firm performance $(r=.25, p<.05)$, personal financial rewards $(r=.34, p<.01)$, and personal fulfilment $(r=.38, p<.01)$ related positively to mental health (Table 6). Vital exhaustion was significantly and negatively associated with the personal fulfilment facet $(r=-.29, p<.05)$ (Table 6). Overall, H7 was supported. Notably, 40 percent of entrepreneurs reported they were not exhausted at all, 43 percent reported medium-level exhaustion, while 17 percent suffered severe exhaustion.

\section{Please insert Table 6 about here}

Finally we addressed Research Question 1 by investigating the relationships between the five facets of Entrepreneurs' Achieved Success and the 'importance' or 'value' that entrepreneurs attach to those five facets as presented in Wach et al. (2016). The following 
pattern of relationships emerged (see Table 7 for German Sample 1 and Table 8 for the Polish Sample): There are positive correlations for all but one facet. In general, the more important a particular success facet is to an entrepreneur, the more likely it is that he or she will achieve that facet. The exception is personal financial rewards, for which importance and actual achievement do not correlate significantly. The pattern of correlations is similar in the German and Polish samples, i.e. the highest correlation exists between value and actual achievement regarding the workplace relationships facet, followed by community impact, personal fulfilment, and firm performance.

We explored to what extent Entrepreneurs' Achieved Success and the 'importance' or 'value' entrepreneurs attach to the success criteria are overlapping concepts. To do so, we conducted CFA in which the items of SES-AS and SES-IS loaded on one common first order factor: 'entrepreneurial success'. This model fitted the data very poorly, both in Germany $\left(C F I=.343, R E M S E A=.126, d f=527, \chi^{2}=2056.543\right)$ and in Poland $(C F I=.376, R E M S E A$ $\left.=.142, d f=527, \chi^{2}=1589.179\right)$. Additionally, we tested a five-factorial model whereby the equivalent valued (SES-IS items) and achieved success criteria (SES-AS items) were forced to load on the same content factor. Similar to the one factor model, the five-factor model fitted the data poorly (German sample: $C F I=.562$, REMSEA $=.105, d f=517, \chi^{2}=$ 1561.437; Polish sample: $C F I=.559$, REMSEA $\left.=.121 d f=517, \chi^{2}=1272.891\right)$. This indicates the 'Entrepreneurs' Valued Success' and Entrepreneurs' Achieved Success are conceptually different. 


\section{Discussion and Conclusions}

Irrespective that entrepreneurs' subjective success is widely viewed to be an important outcome variable in entrepreneurship research, little attention had been paid to its conceptualization and measurement beyond financial firm performance criteria. Our research addresses this gap by conceptualizing Entrepreneurs' Achieved Success as a multi-faceted concept consisting of firm performance, workplace relationship, personal fulfilment, community impact, and personal financial rewards. These five facets align with the Subjective Entrepreneurial Success-Importance Scale (SES-IS) introduced by Wach et al. (2016), which captures success criteria valued by entrepreneurs ('what is important for me'). In contrast, the SES-AS assesses the status of achievement of these criteria ('as is'). Hence, the SES-AS scale measures a unique attribute.

The concept of Entrepreneurs' Achieved Success and the SES-AS instrument refer to the actual achievement of multiple success criteria simultaneously, thus providing a more comprehensive picture of the entrepreneur's situation. Such multiple criteria are in line with psychological and economic research that highlights individuals pursuing multiple goals (Gorgievski et al., 2011) or different types of utility (Orser \& Dyke, 2009) rather than being solely focused on economic returns. This multi-facetted view of success criteria also aligns with emerging work in management scholarship on the 'multi-objective' corporation, which encourages researchers to think beyond financial firm success (Mitchell, Weaver, Agle, Bailey, \& Carlson, 2015). For entrepreneurship research, embracing a multi-faceted view of success enables a more accurate understanding of entrepreneurs' decisions and behaviours, including his or her withdrawal from the firm or its discontinuation. For instance, firm discontinuation is more likely when the overall achievement of success is unsatisfactory, rather than when only one facet remains unfulfilled (e.g., firm performance). 
Our five-factor structure of achieved success partially corresponds with six dimensions of entrepreneurial success as assessed by individual external stakeholders and identified by Razmus and Laguna (2018). These are entrepreneurs' satisfaction, work-life balance, firm social responsibility, firm reputation, satisfaction of employees, and clients' satisfaction. This suggests that business partners, like entrepreneurs themselves, evaluate entrepreneurial success not simply through the lenses of economic indicators.

Our research extends previous conceptualizations and measurements of entrepreneurial success that deal solely with the criteria that entrepreneurs value (Fisher et al., 2014; Gorgievski et al., 2011; Wach et al., 2016). It also overcomes the deficiency of viewing entrepreneurial success purely through the lenses of global firm performance ratings e.g., sales or growth (Richard, Devinney, Yip, \& Johnson, 2009), or of judging a firm's success in relation to competing firms (Lumpkin \& Dess, 2001). Our complex conceptualization of success also challenges self-reported measures of success via satisfaction ratings (Powell \& Eddleston, 2008).

When compared to the assessments of global firm performance and the use of satisfaction ratings that currently dominate entrepreneurship research, the advantage of SESAS is that it captures the separate success criteria that matter to entrepreneurs (see Wach et al., 2016). Following the call of Miller et al. (2013), our research also demonstrates alignment between theory building (conceptualization of Entrepreneurs' Achieved Success as a multifaceted construct) and empirical analysis (operationalization and measurement of five facets of success), in that we have developed a separate theory and one or more hypotheses for each specific facet of success, and treated each facet separately in the analysis. In this way we have obtained accurate and valuable insights into how different facets of achieved success relate to different firm performance indicators and individual level outcomes. For instance, we noticed positive relationships between personal financial rewards as measured via SES-AS and firm 
pre-tax profit and firm net profit, while firm revenue development and employee growth were positively associated with the facet firm performance. This pattern of correlations highlights that the owner decides whether the funds remain in the firm (higher score on firm performance) or are consumed by the owner (higher score on personal financial rewards). We also found a significant correlation $(r=.30, p<.05)$ between revenue development and the personal fulfilment facet, suggesting that leading a high-performing firm gives the entrepreneur more work flexibility, decision making freedom, and opportunities for personal development - all of which are part of the personal fulfilment facet.

While prior research looked at the cross-cultural invariance only with regard to success criteria valued by entrepreneurs, our validation of SES-AS in two samples from different cultures allows us to suggest that achieved success might be a universally applicable multi-faceted construct. The strength of relationships between the items within the single facets was equivalent across cultures, with the single exception of personal fulfilment.

Our multi-faceted structure of achieved success enriches our understanding of the social contribution provided by commercial entrepreneurs. Our results are in line with the view that entrepreneurs contribute to collective interests too (Van de Ven, Sapienza, \& Villanueva, 2007). Thus, our research adds to the recent debate in the literature on the synergy between for-profit and non-profit business objectives, suggesting that altruistic goals can be compatible with, and can even reinforce other entrepreneurial goals (Mickiewicz, Sauka, \& Stephan, 2016).

Prior research found creativity to increase venture performance (Gielnik et al., 2012), and social entrepreneurs to be particularly creative (Shaw \& Carter, 2007); our studies also support a positive link between the firm performance facet, community impact and creativity. Moreover, we found self-reported career success to be particularly highly related to 
entrepreneurs' personal fulfilment, highlighting the centrality of non-pecuniary rewards for entrepreneurs.

Our research also brings together literature on entrepreneurial success and workrelated health and well-being. It demonstrates that achieved success is positively associated with better mental health and less vital exhaustion. In particular, low personal fulfilment seems to be indicative of vital exhaustion - a well-established risk factor of coronary heart disease (Kopp et al., 1998) and one of the components of burn-out (Leiter et al., 2013).

Our research further provides valuable insights concerning the relationship between valued and actual achieved success criteria. Our results suggest that valued success criteria motivate entrepreneurs' behaviour, as manifested in particularly high achievement of high priority goals. Yet our study also confirmed that the value-behaviour relationship is not universally positive for all criteria. The exceptions are individual materialistic goals expressed in the personal financial rewards facet of success; here, desire and achievement were not correlated.

\section{Study Limitations and Implications for Future Research}

For future research on entrepreneurial performance we propose a conceptual approach

(Figure 2) that considers (1) entrepreneurs' valued success criteria and (2) their actual achievement, structured along five facets, and (3) quasi-objective firm-related performance indicators. This model also takes into account the individual and contextual factors that may act as moderators in the relationship between desired and achieved success. The latter builds on more general work by Fischer and Boer (2016) (See Figure 2).

Please insert Figure 2 about here 
We hope future research can empirically test our model. However, due to its complexity, we suggest a stepwise approach to be the most appropriate. We believe it is worth exploring the individual antecedents of entrepreneurs' achieved success (such as personality traits) to generate knowledge on the critical qualifications, predispositions, and training of entrepreneurs. For instance, openness to experience may be a good predictor of high achievement of community impact but not necessarily of firm performance. Greater consideration of how contextual social, cultural, and political factors, and economic framework conditions (including their changes over time) influence entrepreneurs' achieved success is desirable. This is important for an understanding of, for instance, widespread country differences in the performance of entrepreneurs (Zahra \& Wright, 2011). As our research provides insights on the structure of achieved success within a particular time and situational frame, future research might seek to validate if our five facets of success retain their key relevance over time.

As suggested by Razmus and Laguna (2018), who found that there are different structures of success depending on the individual's vs. the firm-level external business partner's evaluations of success, it may be that achieved entrepreneurial success is not an isomorphic construct. Future research may wish to test the structural equivalence across different levels of analysis; for instance, at the firm level, research could aggregate views of employees and co-owners. Methodologically, our cross-sectional study design prevents us from making causal interpretations. For example, we could not investigate the potential reciprocal relationships between valued and achieved success criteria. What an entrepreneur values may be determined by what he or she can achieve and vice versa, and how entrepreneurs understand success may have implications for how they go about developing their firms (Angel, Jenkins, \& Stephens, 2018). Future research can explore how such processes evolve over time to develop a more fine-grained understanding of the conceptual 
differences (and similarities) between valued and achieved success. Particularly, the phenomenographic research approach as applied by Angel et al. (2018) to study how entrepreneurs interpret the meaning of different success criteria might be valuable to the further development of measures of success. An interesting attempt to consider short-term and long-term perspectives of entrepreneurial success has been made by Staniewski and Awruk (2017), who (though retrospectively) assessed success during the past year and in the period since the commencement of the company.

Longitudinal studies can also increase our knowledge regarding the link between achieved success and health. While few studies have investigated such a link (Dijkhuizen et al., 2014; Gorgievski-Duijvesteijn, Giesen, \& Bakker, 2000; Gorgievski et al., 2011), future research may want to use SES-AS to explore more comprehensively the impact of entrepreneurial success (and failure) on the psychological and physical well-being and health of entrepreneurs. This is crucial because entrepreneurs are responsible for their firms; their personal withdrawal due to health problems can lead to firm discontinuation. Future research may also administer SES-IS and SES-AS simultaneously to pinpoint gaps between the importance of success criteria and their actual achievement, as well as to shed light on the consequences of a possible mismatch for firm performance and for the individual entrepreneurs.

New scales often exhibit low reliabilities, especially when the number of items is low (Cortina, 1993). This is also the case for some SES-AS facets since our aim was to develop an economical instrument that is relatively quick to administer. Nevertheless, future studies may wish to use larger samples to further validate the SES-AS and to improve the reliability of SES-AS by extending the number of items per facet. To further validate the community impact facet of success, future research may include entrepreneurs' philanthropic giving, or support of community activities. Studies across countries should explore the facet of 
personal fulfilment, which was not equivalent across countries. It may be that personal fulfilment is particularly sensitive to cultural differences. We also recommend future research to conduct additional qualitative data collection to investigate the cross-cultural differences in more detail, especially to get a better insight into possible additional criteria that apply to specific countries (Staniewski \& Awruk, 2017).

Concerns about common method variance are unlikely to be an alternative explanation for our findings, as the CFA model forcing all items to load on a common factor was a very poor fit to the data. If common method variance was to play a role in our data, a substantially better fit would be expected.

\section{Implications for Practice}

Our findings emphasize that entrepreneurs achieve multiple success criteria, challenging the traditional view that entrepreneurial success is commensurate only with financial firm performance. Educators may want to highlight such varied entrepreneurial career outcomes when attracting new generations to entrepreneurship. In particular, variety and opportunities for personal development and career progress were found to be valued job attributes for the

millennial generation (Terjesen, Vinnicombe, \& Freeman, 2007), and our study suggests these can be fulfilled by entrepreneurship.

Entrepreneurs can benefit from our research by systematically monitoring their success using the SES-AS measurement instrument. This will increase their awareness of success fluctuations and may prevent them from neglecting specific success domains. Based on the analysis of self-assessed deficits (and strengths) using SES-AS and SES-IS, organizations supporting entrepreneurs could develop interventions to help the entrepreneurs to derive more satisfaction from their work and achieve the criteria they value most. For 
instance, achievement of workplace relationships can be assisted by leadership training or coaching. Furthermore, to uncover 'blind spots', entrepreneurs' self-evaluations of achieved success can be complemented by peer or employee ratings. Future research can also use the SES-AS instrument to obtain 360-degree feedback evaluations of achievement, including firm stakeholders in the measure.

Based on our findings, we suggest that a high achievement of success can possibly act as a job resource, leading to positive workplace outcomes and diminishing the negative effect of stressors. Stressors can potentially result from poor performance in relevant success domains, for instance when entrepreneurs lack personal fulfilment. Our notion that health and success are positively associated may direct entrepreneurs' attention to implement stress reduction techniques, for instance via training of emotional competencies or relaxation techniques.

More generally, we believe that public communication of our finding that the successful entrepreneurs are those who achieve multiple success criteria simultaneously, may reduce the pressure on entrepreneurs to excel solely in the financial aspect. To avoid frustration and business discontinuation, achievement of non-pecuniary rewards should be accepted to be a legitimate goal of entrepreneurship. 


\title{
Appendix 1
}

\section{Development of the Subjective Entrepreneurial Success-Achievement Scale}

\author{
(SES-AS, Study 1)
}

\section{The SES-AS}

Scale instruction:

How successful have you been in the past year in achieving the following aspects? Please indicate your achievement on the scale ranging from 1 'not achieved at all' to 5 'absolutely achieved'.

\section{Items}

Firm Performance

Firm profitability (e.g., high returns) ${ }^{a}$

Turnover/sales

Profit growth

Increased market share (e.g., company expansion)

Workplace Relationships

Strong customer relationships ${ }^{\text {a }}$

Employee satisfaction

Supportive firm culture

Social responsibility for employees ${ }^{d}$

Strong employee relationships ${ }^{b}$

Employee loyalty ${ }^{b}$

Personal Fulfilment

Work-life balance (e.g., free time) ${ }^{\text {a }}$

Personal work flexibility

Own decision-making

Personal development

Maintenance of private contacts ${ }^{b c}$

Community Impact

Social responsibility for your employees ${ }^{d}$

Firm social contribution

Environmentally friendly firm (e.g., recycling)

Social recognition (e.g., good firm reputation) ${ }^{b}$

Personal Financial Rewards

Personal income growth

Personal financial security

Ability to afford a lot

\footnotetext{
Bold - items in final SES-AS version. Italics - subscales.

a item removed in the first step based on the first $C F A$.

${ }^{\mathrm{b}}$ item added to increase reliability after first $C F A$.

${ }^{c}$ item removed after the second $C F A$.

ditem moved from facet community impact to workplace relationships facet after second $C F A$.
} 
Table 1

Tests of alternative models for SES-AS (Study 1)

\begin{tabular}{|c|c|c|c|c|c|c|c|c|}
\hline Model description & Items & $x^{2}$ & $d f$ & $\Delta \chi^{2}$ & $\Delta d f$ & $\Delta C F I$ & CFI & $R M S E A$ \\
\hline \multicolumn{9}{|l|}{ German Sample 1} \\
\hline $\begin{array}{l}\text { M1 Hypothesized five- } \\
\text { facet model }\end{array}$ & 17 & 209.835 & 109 & & & & .896 & .072 \\
\hline $\begin{array}{l}\text { M1.1 Revised five- } \\
\text { facet model }\end{array}$ & 17 & 192.720 & 106 & $17.115^{* *}$ & 3 & .023 & .919 & .068 \\
\hline \multicolumn{9}{|l|}{ Alternative models } \\
\hline $\begin{array}{l}\text { M2 One latent factor } \\
\text { model }\end{array}$ & 17 & 598.218 & 133 & $388.383 * *$ & 24 & .377 & .519 & .140 \\
\hline $\begin{array}{l}\text { M3 Second order latent } \\
\text { factor model with five } \\
\text { first order factors }\end{array}$ & 17 & 304.612 & 118 & $94.770 * *$ & 9 & .089 & .807 & .094 \\
\hline \multicolumn{9}{|l|}{ German Sample 2} \\
\hline $\begin{array}{l}\text { M1.2 Extended five- } \\
\text { facet model }\end{array}$ & 21 & 410.474 & 179 & & & & .825 & .109 \\
\hline $\begin{array}{l}\text { M1.3 Final five-facet } \\
\text { model }\end{array}$ & 17 & 159.931 & 109 & 250.543 & 70 & .127 & .952 & .065 \\
\hline \multicolumn{9}{|l|}{ Polish Sample } \\
\hline $\begin{array}{l}\text { M1.3 Final five-facet } \\
\text { model }\end{array}$ & 17 & 119.473 & 109 & & & & .987 & .031 \\
\hline
\end{tabular}

SES-AS: Subjective Entrepreneurial Success-Achievement Scale.

$C F I$ : Comparative Fit Index; RMSEA: Root Mean Square Error of Approximation.

$* * p<.01$. 
Table 2

Descriptive statistics, reliabilities, correlations and validity of SES-AS (Study 1)

\begin{tabular}{|c|c|c|c|c|c|c|c|c|c|c|c|c|}
\hline Success facets (SES-AS subscales) & Mean & $S D$ & $\alpha$ & $C R$ & $A V E$ & $M S V$ & $A S V$ & $\begin{array}{l}\text { Item } \\
(N)\end{array}$ & 1 & 2 & 3 & 4 \\
\hline \multicolumn{13}{|l|}{ German Sample 1} \\
\hline Firm performance & 3.35 & .72 & .80 & 0.81 & 0.52 & 0.74 & 0.32 & 4 & & & & \\
\hline Workplace relationships & 4.00 & .63 & .70 & 0.71 & 0.46 & 0.62 & 0.40 & 3 & $.49 * *$ & & & \\
\hline Personal fulfilment & 3.74 & .65 & .65 & 0.68 & 0.36 & 0.45 & 0.28 & 4 & $.49 * *$ & $.36^{* *}$ & & \\
\hline Community impact & 3.57 & .70 & .53 & 0.53 & 0.28 & 0.62 & 0.40 & 3 & $.18 *$ & $.33 * *$ & $.25 * *$ & \\
\hline Personal financial rewards & 3.15 & .88 & .79 & 0.78 & 0.54 & 0.69 & 0.24 & 3 & $.16^{*}$ & $.29 * *$ & $.32 * *$ & $.53 * *$ \\
\hline \multicolumn{13}{|l|}{ German Sample 2} \\
\hline Firm performance rewards & 2.95 & 1.02 & .83 & 0.84 & 0.63 & 0.66 & 0.27 & 3 & & & & \\
\hline Workplace relationships & 4.04 & .78 & .91 & 0.91 & 0.68 & 0.29 & 0.14 & 5 & .17 & & & \\
\hline Personal fulfilment & 3.84 & .75 & .60 & 0.67 & 0.43 & 0.35 & 0.29 & 3 & $.36^{* *}$ & $.50 * *$ & & \\
\hline Community impact & 3.49 & .89 & .81 & 0.81 & 0.59 & 0.32 & 0.20 & 3 & $.29 * *$ & $.35 * *$ & $.35 * *$ & \\
\hline Personal financial rewards & 2.92 & 1.05 & .88 & 0.88 & 0.71 & 0.66 & 0.30 & 3 & $.79 * *$ & $.27 * *$ & $.40 * *$ & $.26^{* *}$ \\
\hline \multicolumn{13}{|l|}{ Polish Sample } \\
\hline Firm performance & 3.15 & .89 & .80 & 0.83 & 0.64 & 0.50 & 0.19 & 3 & & & & \\
\hline Workplace relationships & $3.65^{*}$ & 1.11 & 88 & 0.90 & 0.65 & 0.25 & 0.15 & 5 & $.35 * *$ & & & \\
\hline Personal fulfilment & 3.92 & .72 & .67 & 0.70 & 0.46 & 0.45 & 0.19 & 3 & $.32 * *$ & $.21 *$ & & \\
\hline Community impact & $2.86^{* *}$ & .95 & .69 & 0.69 & 0.42 & 0.16 & 0.10 & 3 & $.24 *$ & $.35^{* *}$ & $.23 *$ & \\
\hline Personal financial rewards & 3.14 & .93 & .83 & 0.83 & 0.61 & 0.50 & 0.32 & 3 & $.62 * *$ & $.46^{* *}$ & $.54 * *$ & $.23 *$ \\
\hline
\end{tabular}

SES-AS: Subjective Entrepreneurial Success-Achievement Scale.

Germany Sample $1(n=179)$, Germany Sample $2(n=110)$, Polish Sample $(n=101)$

$\alpha$ : Cronbach's Alpha; $C R$ : Composite Reliability; $A V E$ : Average Variance Extracted; $M S V$ : Maximum Shared Variance; $A S V$ : Average Shared Variance.

${ }^{* *} p<.01 ; * p<.05$. 
Table 3

Cross-cultural replication of five-facet structure of SES-AS

(German sample 2, Polish sample, Study 2)

\begin{tabular}{lllllll}
\hline Model & $\chi^{2}$ & $\boldsymbol{d f}$ & $\Delta \chi^{2}$ & $\Delta \boldsymbol{d f}$ & $\boldsymbol{C F I}$ & $\boldsymbol{R M S E \boldsymbol { A }}$ \\
\hline $\begin{array}{l}\text { M1. Configural invariance } \\
\text { (Unconstrained model) }\end{array}$ & 279.393 & 218 & & & .967 & .037 \\
$\begin{array}{l}\text { M2. Factor loadings invariance } \\
\text { (Constrained model) }\end{array}$ & 330.383 & 230 & $50.990^{* *}$ & 12 & .946 & .046 \\
Partial factor loading invariance of five SES-AS facets compared to configural model & & \\
M2.1. Firm performance & 281.279 & 220 & $1.886 \mathrm{~ns}$ & 2 & .967 & .037 \\
M2.2. Workplace relationships & 280.995 & 221 & $1.602 \mathrm{~ns}$ & 3 & .968 & .036 \\
M2.3. Personal fulfilment & 299.247 & 220 & $19.854 * *$ & 2 & .958 & .042 \\
M2.4. Community impact & 282.057 & 219 & $2.665 \mathrm{~ns}$ & 1 & .966 & .037 \\
M2.5. Personal financial rewards & 280.756 & 220 & $1.364 \mathrm{~ns}$ & 2 & .967 & .036 \\
\hline
\end{tabular}

SES-AS: Subjective Entrepreneurial Success-Achievement Scale.

Germany $(n=110)$, Poland $(n=101)$.

$* * p<.01$. 
Table 4

Criterion validity of SES-AS (German Sample 2, Study 3)

\begin{tabular}{|c|c|c|c|c|c|c|c|c|c|c|c|c|c|}
\hline Variables & $N$ & 1 & 2 & 3 & 4 & 5 & 6 & 7 & 8 & 9 & 10 & 11 & 12 \\
\hline $\begin{array}{l}\text { SES-AS } \\
\text { 1. Firm performance }\end{array}$ & 110 & & & & & & & & & & & & \\
\hline 2. Personal financial rewards & 110 & $.79 * *$ & & & & & & & & & & & \\
\hline \multicolumn{14}{|l|}{ Criteria } \\
\hline 3. Firm pre-tax profit 2009 & 49 & .12 & $.33^{*}$ & & & & & & & & & & \\
\hline 4. Firm pre-tax profit 2010 & 51 & .17 & $.35^{*}$ & $.75 * *$ & & & & & & & & & \\
\hline 5. Firm pre-tax profit 2011 & 53 & .14 & $.33^{*}$ & $.65 * *$ & $.97 * *$ & & & & & & & & \\
\hline 6. Firm net profit 2009 & 40 & .29 & $.37 *$ & $.44^{*}$ & .25 & .25 & & & & & & & \\
\hline 7. Firm net profit 2010 & 54 & $.32 *$ & $.45 * *$ & $.42 * *$ & $.45 * *$ & $.35 *$ & $.44 * *$ & & & & & & \\
\hline 8. Firm net profit 2011 & 49 & .19 & $.38 * *$ & $.96 * *$ & $.95 * *$ & $.96^{* *}$ & .24 & $.44 * *$ & & & & & \\
\hline 9. Revenue development 2008/2009 & 50 & $.36^{* *}$ & .16 & .05 & .09 & .10 & $.38^{*}$ & .02 & .10 & & & & \\
\hline 10. Revenue development 2009/2010 & 51 & .27 & .20 & -.06 & .03 & -.02 & -.14 & .15 & -.00 & $.32 *$ & & & \\
\hline 11. Revenue development $2010 / 2011^{\mathrm{a}}$ & 52 & $.41 * *$ & .23 & -.06 & -.04 & -.03 & .04 & -.19 & -.03 & .27 & .23 & & \\
\hline 12. Firm employee growth & 103 & $.26^{* *}$ & .14 & -.02 & -.05 & -.02 & .09 & -.06 & -.01 & $.53 * *$ & -.07 & $.45^{* *}$ & \\
\hline 13. Entrepreneur annual income & 80 & $.23 *$ & $.41 * *$ & $.79 * *$ & $.73 * *$ & $.67 * *$ & .28 & $.44^{* *}$ & $.79 * *$ & .14 & .03 & -.17 & .06 \\
\hline
\end{tabular}

SES-AS: Subjective Entrepreneurial Success-Achievement Scale.

Germany $(N=110)$

${ }^{\mathrm{a}}$ significant correlation with facet personal fulfilment $(r=.30, p<.05)$

$* * p<.01 ; * p<.05$. 
Table 5

Criterion validity of SES-AS (German Sample 2, Study 3)

\begin{tabular}{|c|c|c|c|c|c|c|c|c|c|c|}
\hline Variables & Mean & $S D$ & 1 & 2 & 3 & 4 & 5 & 6 & 7 & 8 \\
\hline \multicolumn{11}{|l|}{ SES-AS } \\
\hline 1. Firm performance & 2.95 & 1.02 & & & & & & & & \\
\hline 2. Workplace relationships & 4.04 & .78 & .17 & & & & & & & \\
\hline 3. Personal fulfilment & 3.84 & .75 & $.36^{* *}$ & $.50 * *$ & & & & & & \\
\hline 4. Community impact & 3.49 & .89 & $.29 * *$ & $.35^{* *}$ & $.35^{* *}$ & & & & & \\
\hline 5. Personal financial rewards & 2.92 & 1.05 & $.79 * *$ & $.27 * *$ & $.40 * *$ & $.25 * *$ & & & & \\
\hline \multicolumn{11}{|l|}{ Criteria } \\
\hline $\begin{array}{l}\text { 6. Satisfaction with financial } \\
\text { situation }\end{array}$ & 4.3 & 1.68 & $.49 * *$ & $.26^{* *}$ & $.41^{* *}$ & .16 & $.68 * *$ & & & \\
\hline $\begin{array}{l}\text { 7. Global firm financial } \\
\text { success }\end{array}$ & 3.34 & .99 & $.60 * *$ & $.24^{*}$ & $.35^{* *}$ & $.32 * *$ & $.67 * *$ & $.61 * *$ & & \\
\hline $\begin{array}{l}\text { 8. Self-reported career } \\
\text { success }^{\text {a }}\end{array}$ & 3.83 & .75 & $.37 * *$ & $.30 * *$ & $.47 * *$ & $.32 * *$ & $.42 * *$ & $.49 * *$ & $.46^{* *}$ & \\
\hline 9. Creativity & 5.5 & .95 & $.29 * *$ & .07 & $.23^{*}$ & $.24 *$ & .16 & .07 & $.21 *$ & $.26 * *$ \\
\hline
\end{tabular}

SES-AS: Subjective Entrepreneurial Success-Achievement Scale.

Germany $(N=110)$.

${ }^{a}$ Mean and standard deviation of the sum was calculated.

$* * p<.01 ; * p<.05$.

Table 6. Criterion validity of SES-AS (Polish Sample, Study 3).

\begin{tabular}{|c|c|c|c|c|c|c|c|c|c|}
\hline Variables & Mean & $S D$ & 1 & 2 & 3 & 4 & 5 & 6 & 7 \\
\hline \multicolumn{10}{|l|}{ SES-AS } \\
\hline 1. Firm performance & 3.15 & .89 & & & & & & & \\
\hline 2. Workplace relationships & 3.65 & 1.11 & $.35 * *$ & & & & & & \\
\hline 3. Personal fulfilment & 3.92 & .72 & $.32 * *$ & $.21 *$ & & & & & \\
\hline 4. Community impact & 2.86 & .95 & $.24 *$ & $.35 * *$ & $.23 *$ & & & & \\
\hline $\begin{array}{l}\text { 5. Personal financial } \\
\text { rewards }\end{array}$ & 3.14 & .93 & $.62 * *$ & $.46^{* *}$ & $.54 * *$ & $.23^{*}$ & & & \\
\hline \multicolumn{10}{|l|}{ Criteria } \\
\hline 6. Global firm success & 3.43 & 1.03 & $.59 * *$ & $.28 * *$ & $.26^{* *}$ & $.22 *$ & $.55^{* *}$ & & \\
\hline 7. Mental health & 3.24 & .55 & $.25^{*}$ & .15 & $.38 * *$ & $.20^{*}$ & $.34 * *$ & $.22 *$ & \\
\hline 8. Vital exhaustion ${ }^{a}$ & 5.31 & 5.37 & -.17 & -.20 & $-.29 *$ & -.20 & -.23 & -.15 & $-.65 * *$ \\
\hline
\end{tabular}

SES-AS: Subjective Entrepreneurial Success-Achievement Scale.

Poland $(N=101)$.

${ }^{\text {a }}$ Mean and standard deviation of the sum was calculated.

$* * p<.01 ; * p<.05$. 
Table 7. Correlations between SES-IS and SES-AS (German Sample 1, Study 3).

\begin{tabular}{|c|c|c|c|c|c|c|c|c|c|c|c|}
\hline Subscales (success facets) & Mean & $S D$ & 1 & 2 & 3 & 4 & 5 & 6 & 7 & 8 & 9 \\
\hline \multicolumn{12}{|l|}{ SES-IS } \\
\hline 1. Firm performance importance & 3.79 & .83 & & & & & & & & & \\
\hline 3. Personal fulfilment importance & 4.34 & .53 & $.26 * *$ & $.47 * *$ & & & & & & & \\
\hline 4. Community impact importance & 3.49 & .84 & $.20 * *$ & $.39 * *$ & $.28 * *$ & & & & & & \\
\hline 5. Personal financial rewards importance & 3.64 & .80 & $.49 * *$ & .04 & $.36 * *$ & .03 & & & & & \\
\hline 6. Firm performance achievement & 3.28 & .87 & $.25 * *$ & $.16^{*}$ & .04 & .14 & .02 & & & & \\
\hline 7. Workplace relationships achievement & 4.03 & .66 & .05 & $.50 * *$ & $.19^{*}$ & $.43^{* *}$ & .04 & $.18^{*}$ & & & \\
\hline 8. Personal fulfilment achievement & 4.01 & .67 & $.15^{*}$ & $.34 * *$ & $.37 * *$ & .08 & .13 & $.25^{* *}$ & $.47 * *$ & & \\
\hline 9. Community impact achievement & 3.35 & .78 & .14 & $.31 * *$ & $.19^{*}$ & $.44^{* *}$ & .05 & $.32 * *$ & $.35^{* *}$ & $.32 * *$ & \\
\hline 10. Personal financial rewards achievement & 3.15 & .88 & .03 & .10 & .12 & .07 & -.04 & $.53 * *$ & $.16^{*}$ & $.23 * *$ & $.26^{* *}$ \\
\hline
\end{tabular}

SES-IS: Subjective Entrepreneurial Success-Importance Scale, SES-AS: Subjective Entrepreneurial Success-Achievement Scale.

Germany $(N=179)$.

$* * p<.01 ; * p<.05$. 
Table 8. Correlations between SES-IS and SES-AS (Polish Sample, Study 3).

\begin{tabular}{|c|c|c|c|c|c|c|c|c|c|c|c|}
\hline Subscales (success facets) & Mean & $S D$ & 1 & 2 & 3 & 4 & 5 & 6 & 7 & 8 & 9 \\
\hline \multicolumn{12}{|l|}{ SES-IS } \\
\hline 1. Firm performance importance & 4.20 & .66 & & & & & & & & & \\
\hline 2. Workplace relationships importance & 4.42 & .77 & $.38 * *$ & & & & & & & & \\
\hline 3. Personal fulfilment importance & 4.55 & .43 & $.29 * *$ & $.22 *$ & & & & & & & \\
\hline 4. Community impact importance & 3.37 & 1.15 & $.41 * *$ & $.51 * *$ & $.26 * *$ & & & & & & \\
\hline 5. Personal financial rewards importance & 4.24 & .69 & $.37 * *$ & $.29 * *$ & $.38 * *$ & $.27 * *$ & & & & & \\
\hline \multicolumn{12}{|l|}{ SES-AS } \\
\hline 6. Firm performance achievement & 3.15 & .89 & $.23 *$ & .13 & -.03 & .19 & -.09 & & & & \\
\hline 7. Workplace relationships achievement & 3.65 & 1.11 & $.24 *$ & $.67 * *$ & .09 & $.53 * *$ & .11 & $.35 * *$ & & & \\
\hline 8. Personal fulfilment achievement & 3.92 & .72 & .06 & .02 & $.27 * *$ & .04 & .08 & $.32 * *$ & $.21 *$ & & \\
\hline 9. Community impact achievement & 2.86 & .95 & .07 & $.23^{*}$ & .15 & $.52 * *$ & -.04 & $.24 *$ & $.35 * *$ & $.23 *$ & \\
\hline 10. Personal financial rewards achievement & 3.14 & .93 & .05 & $.20 *$ & .10 & .17 & .04 & $.62 * *$ & $.46^{* *}$ & $.54 * *$ & $.23 *$ \\
\hline
\end{tabular}

SES-IS: Subjective Entrepreneurial Success-Importance Scale, SES-AS: Subjective Entrepreneurial Success-Achievement Scale.

Poland $(N=101)$.

$* * p<.01 ; * p<.05$. 


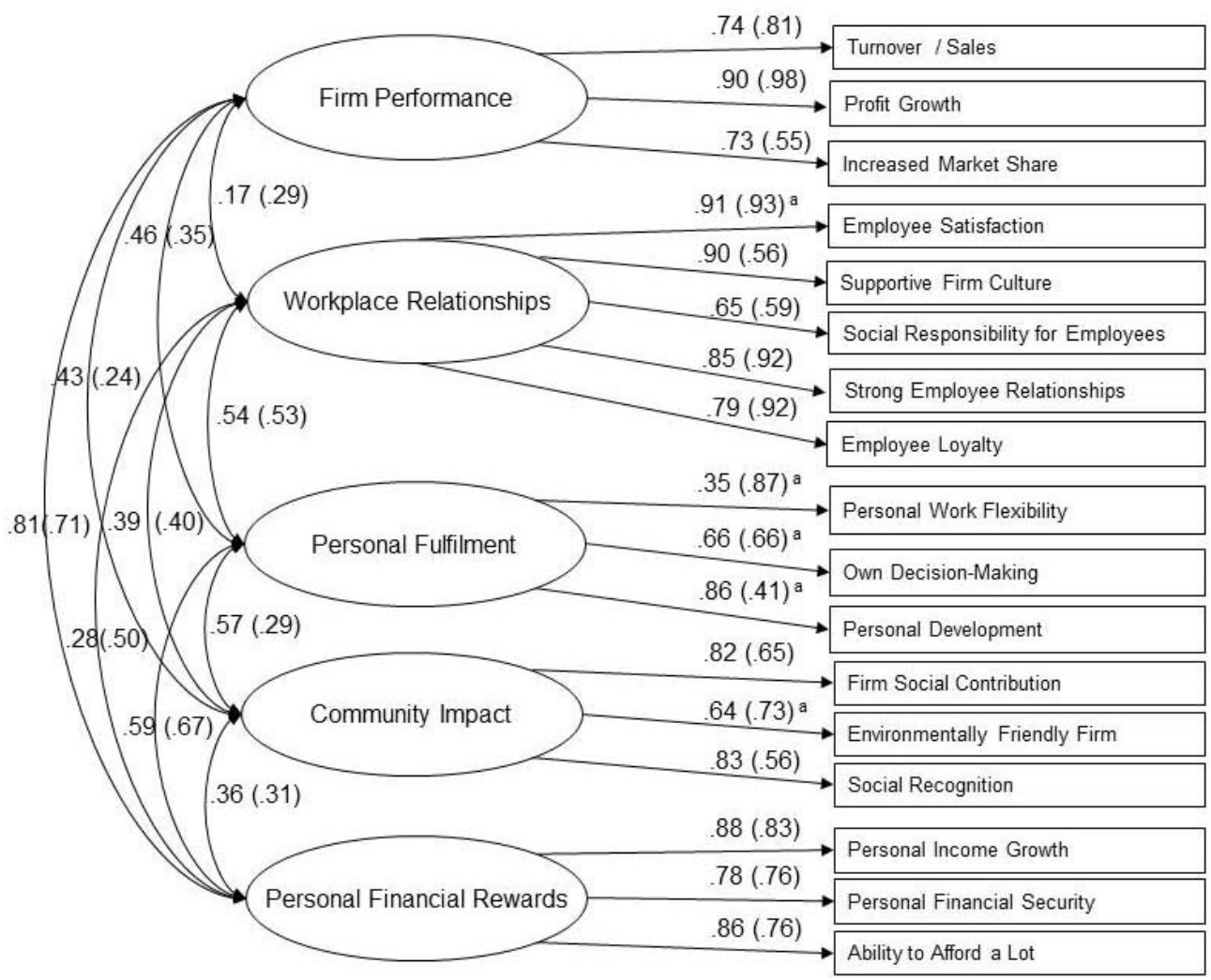

Figure 1. Factorial structure of SES-AS.

Standardized factor loadings and correlations are displayed. Values in brackets refer to the Polish sample $(n=101)$; other values refer to the German sample $(n=110)$.

${ }^{a}$ indicates significant differences in factor loadings across samples (cf. Table 3). Sample difference test refers to the non-standardized loadings as standardized values are not directly comparable across samples.

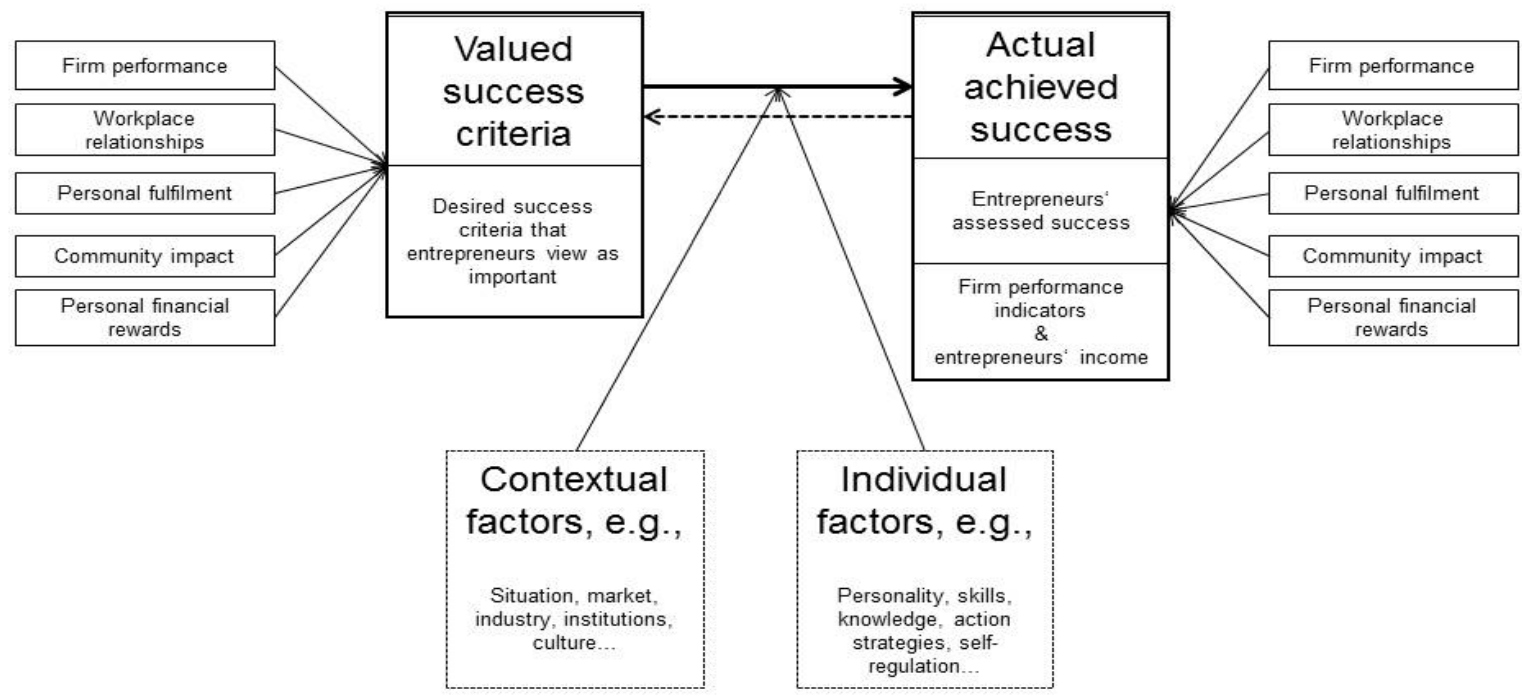

Figure 2. Conceptual model of entrepreneurial performance.

Shapes with dashed lines represent possible moderators. The dashed arrow illustrates possible feedback from achieved success criteria to valued success criteria. 


\section{References}

Angel, P., Jenkins, A., \& Stephens, A. (2018). Understanding entrepreneurial success: A phenomenographic approach. International Small Business Journal, 0(0), 1-26. doi:10.1177/0266242618768662

Appels, A., \& Mulder, P. (1988). Excess fatigue as a precursor of myocardial infarction. European Heart Journal, 9(7), 758-764. doi:10.1093/eurheartj/9.7.758

Arbuckle, J. L. (2014). Amos (Version 23). Chicago: IBM SPSS.

Baer, M., \& Oldham, G. R. (2006). The Curvilinear Relation Between Experienced Creative Time Pressure and Creativity: Moderating Effects of Openness to Experience and Support for Creativity. Journal of Applied Psychology, 91(4), 963-970.

Bagozzi, R. P., \& Yi, Y. (1988). On the evaluation of structural equation models. Journal of the Academy of Marketing Science, 16(1), 74-94. doi:10.1007/bf02723327

Bates, T. (2005). Analysis of young, small firms that have closed: delineating successful from unsuccessful closures. Journal of Business Venturing, 20(3), 343-358. doi:10.1016/j.jbusvent.2004.01.003

Bellach, B.-M., Knopf, H., \& Thefeld, W. (1998). [The German Health Survey. 1997/98]. Gesundheitswesen (Bundesverband der Arzte des Offentlichen Gesundheitsdienstes), 60, S59-68.

Benzing, C., \& Chu, H. M. (2009). A comparison of the motivations of small business owners in Africa. Journal of Small Business and Enterprise Development, 16(1), 6077. doi:10.1108/14626000910932881

Bilton, C. (2007). Management and creativity: From creative industries to creative management: Blackwell Publishing.

Brammer, S., Millington, A., \& Rayton, B. (2007). The contribution of corporate social responsibility to organizational commitment. The International Journal of Human Resource Management, 18(10), 1701-1719. doi:10.1080/09585190701570866

Brodbeck, F. C., Frese, M., \& Javidan, M. (2002). Leadership made in Germany: Low on compassion, high on performance. Academy of Management Executive, 16(1), 16-29. doi:10.5465/AME.2002.6640111

Bullinger, M., \& Kirchberger, I. (1998). Fragebogen zum Gesundheitszustand: SF-36; Handanweisung: Hogrefe, Verlag für Psychologie.

Busenitz, L. W., \& Barney, J. B. (1997). Differences between entrepreneurs and managers in large organizations: Biases and heuristics in strategic decision-making. Journal of Business Venturing, 12(1), 9-30. doi:10.1016/S0883-9026(96)00003-1

Byrne, B. M., Shavelson, R. J., \& Muthen, B. (1989). Testing for the Equivalence of Factor Covariance and Mean Structures - the Issue of Partial Measurement Invariance. Psychological Bulletin, 105(3), 456-466. doi:Doi 10.1037/0033-2909.105.3.456

Cassar, G. (2007). Money, money, money? A longitudinal investigation of entrepreneur career reasons, growth preferences and achieved growth. Entrepreneurship \& Regional Development, 19(1), 89-107. doi:10.1080/08985620601002246

Chandler, G. N., \& Hanks, S. H. (1993). Measuring the performance of emerging businesses: A validation study. Journal of Business Venturing, 8(5), 391-408. doi:10.1016/08839026(93)90021-V

Chandler, G. N., \& Jansen, E. (1992). The founder's self-assessed competence and venture performance. Journal of Business Venturing, 7(3), 223-236. doi:10.1016/08839026(92)90028-p

Cooper, A. C., \& Artz, K. W. (1995). Determinants of satisfaction for entrepreneurs. Journal of Business Venturing, 10 (6), 439-457.

Cortina, J. M. (1993). What is coefficient alpha? An examination of theory and applications. Journal of Applied Psychology, 78(1), 98-104. 
Curtin, R. T., \& Reynolds, P. D. (2008). Business Creation in the United States: Panel Study of Entrepreneurial Dynamics II Initial Assessment. Foundations and Trends ${ }^{\circledR}$ in Entrepreneurship, 4(3), 155-307. doi:10.1561/0300000022

Dess, G. G., \& Robinson, R. B. (1984). Measuring organizational performance in the absence of objective measures: the case of the privately-held firm and conglomerate business unit. Strategic Management Journal, 5(3), 265-273.

DeTienne, D. R., Shepherd, D. A., \& De Castro, J. O. (2008). The fallacy of "only the strong survive": The effects of extrinsic motivation on the persistence decisions for underperforming firms. Journal of Business Venturing, 23(5), 528-546. doi:10.1016/j.jbusvent.2007.09.004

Dijkhuizen, J., Gorgievski, M., van Veldhoven, M., \& Schalk, R. (2014). Feeling successful as an entrepreneur: a job demands - resources approach. International Entrepreneurship and Management Journal, 12(2), 555-573. doi:10.1007/s11365014-0354-z

Dillman, D. A. (2000). Mail and internet surveys: The tailored design method (Vol. 2): Wiley New York.

Eddleston, K. A., \& Powell, G. N. (2012). Nurturing Entrepreneurs' Work-Family Balance: A Gendered Perspective. Entrepreneurship Theory and Practice, 36(3), 513-541. doi:10.1111/j.1540-6520.2012.00506.x

Edelman, L. F., Brush, C. G., Manolova, T. S., \& Greene, P. G. (2010). Start-up Motivations and Growth Intentions of Minority Nascent Entrepreneurs. Journal of Small Business Management, 48(2), 174-196.

Fagenson, E. A. (1993). Personal Value-Systems of Men and Women Entrepreneurs Versus Managers. Journal of Business Venturing, 8(5), 409-430. doi:Doi 10.1016/08839026(93)90022-W

Fischer, R. (2006). Congruence and functions of personal and cultural values: Do my values reflect my culture's values? Personality and Social Psychology Bulletin, 32(11), 1419-1431. doi:10.1177/0146167206291425

Fischer, R., \& Boer, D. (2016). Values: the dynamic nexus between biology, ecology and culture. Current Opinion in Psychology, 8, 155-160. doi:10.1016/j.copsyc.2015.12.009

Fisher, R., Maritz, A., \& Lobo, A. (2014). Evaluating entrepreneurs' perception of success. International Journal of Entrepreneurial Behavior \& Research, 20(5), 478-492. doi:10.1108/ijebr-10-2013-0157

Fornell, C., \& Larcker, D. F. (1981). Structural equation models with unobservable variables and measurement error: Algebra and statistics. Journal of marketing research, 382388. doi: $10.2307 / 3150980$

Gielnik, M. M., Frese, M., Graf, J. M., \& Kampschulte, A. (2012). Creativity in the opportunity identification process and the moderating effect of diversity of information. Journal of Business Venturing, 27(5), 559-576. doi:10.1016/j.jbusvent.2011.10.003

Gimeno, J., Folta, T. B., Cooper, A. C., \& Woo, C. Y. (1997). Survival of the Fittest? Entrepreneurial Human Capital and the Persistence of Underperforming Firms. Administrative Science Quarterly, 42(4), 750-783.

Gorgievski-Duijvesteijn, M. J., Giesen, C. W. M., \& Bakker, A. B. (2000). Financial problems and health complaints among farm couples: Results of a 10-year follow-up study. Journal of Occupational Health Psychology, 5(3), 359-373. doi:10.1037/10768998.5.3.359

Gorgievski, M. J., Ascalon, E. M., \& Stephan, U. (2011). Small Business Owners' Success Criteria, a Values Approach to Personal Differences. Journal of Small Business Management, 49(2), 207-232. doi:doi:10.1111/j.1540-627X.2011.00322.x 
Grant, S., \& Ferris, K. (2012). Identifying sources of occupational stress in entrepreneurs for measurement. International Journal of Entrepreneurial Venturing, 4(4), 351-373. doi:10.1504/ijev.2012.049828

Gupta, A. K., \& Govindarajan, V. (1986). Resource Sharing Among Sbus: Strategic Antecedents and Administrative Implications. Academy of Management Journal, 29(4), 695-714. doi:10.2307/255940

Hair, J. F., Black, W. C., Babin, B. J., Anderson, R. E., \& Tatham, R. L. (2006). Multivariate data analysis 6th Edition. New Jersey: Pearson Education.

Hair , J. F., Hult, G. M., Ringle, C., \& Sarstedt, M. (2016). A primer on partial least squares structural equation modeling (PLS-SEM). Thousand Oaks, CA: Sage Publications.

Harada, N. (2003). Who succeeds as an entrepreneur? An analysis of the post-entry performance of new firms in Japan. Japan and the World Economy, 15(2), 211-222. doi:10.1016/s0922-1425(02)00002-6

Harter, J. K., Schmidt, F. L., \& Hayes, T. L. (2002). Business-Unit-Level Relationship Between Employee Satisfaction, Employee Engagement, and Business Outcomes: A Meta-Analysis. Journal of Applied Psychology, 87(2), 268-279.

House, R. J., Hanges, P. J., Javidan, M., Dorfman, P. W., \& Gupta, V. (2004). Culture, leadership, and organizations: The GLOBE study of 62 societies: Sage publications.

Jayawarna, D., Rouse, J., \& Kitching, J. (2011). Entrepreneur motivations and life course. International Small Business Journal, 31(1), 34-56. doi:10.1177/0266242611401444

Kauanui, S. K., Thomas, K. D., Rubens, A., \& Sherman, C. L. (2010). Entrepreneurship and Spirituality: A Comparative Analysis of Entrepreneurs' Motivation. Journal of Small Business and Entrepreneurship, 23(4), 621-635. doi:10.1080/08276331.2010.10593505

Kopp, M. S., Falger, P. R., Appels, A., \& Szedmak, S. (1998). Depressive symptomatology and vital exhaustion are differentially related to behavioral risk factors for coronary artery disease. Psychosomatic Medicine, 60(6), 752-758.

Kunin, T. (1955). The construction of a new type of attitude measure. Personnel Psychology, $8,65-78$.

Kuratko, D. F., Hornsby, J. S., \& Naffziger, D. W. (1997). An examination of owner's goals in sustaining entrepreneurship. Journal of Small Business Management, 35(1), 24-33.

Leiter, M. P., Hakanen, J. J., Ahola, K., Toppinen-Tanner, S., Koskinen, A., \& Väänänen, A. (2013). Organizational predictors and health consequences of changes in burnout: A 12-year cohort study. Journal of Organizational Behavior, 34(7), 959-973. doi:10.1002/job.1830

Lukes, M., \& Stephan, U. (2012). Nonprofit Leaders and for-Profit Entrepreneurs: Similar People with Different Motivation. Ceskoslovenska Psychologie, 56(1), 41-55.

Lumpkin, G. T., \& Dess, G. G. (2001). Linking two dimensions of entrepreneurial orientation to firm performance: The moderating role of environment and industry life cycle. Journal of Business Venturing, 16(5), 429-+. doi:Doi 10.1016/S08839026(00)00048-3

Maseland, R., \& van Hoorn, A. (2009). Explaining the negative correlation between values and practices: A note on the Hofstede-GLOBE debate. Journal of International Business Studies, 40(3), 527-532. doi:10.1057/jibs.2008.68

Mickiewicz, T., Sauka, A., \& Stephan, U. (2016). On the compatibility of benevolence and self-interest: Philanthropy and entrepreneurial orientation. International Small Business Journal, 34(3), 303-328. doi:10.1177/0266242614555245

Miller, C. C., Washburn, N. T., \& Glick, W. H. (2013). Perspective-The Myth of Firm Performance. Organization Science, 24(3), 948-964. doi:10.1287/orsc.1120.0762

Mitchell, R. K., Weaver, G. R., Agle, B. R., Bailey, A. D., \& Carlson, J. (2015). Stakeholder Agency and Social Welfare: Pluralism and Decision Making in the Multi-Objective 
Corporation. Academy of Management Review, 41(2), 252-275.

doi:10.5465/amr.2013.0486

Orser, B., \& Dyke, L. (2009). The Influence of Gender and Occupational-Role on

Entrepreneurs' and Corporate Managers' Success Criteria. Journal of Small Business \& Entrepreneurship, 22(3), 327-353. doi:10.1080/08276331.2009.10593459

Parker, S. C. (2009). Why do small firms produce the entrepreneurs? The Journal of SocioEconomics, 38(3), 484-494.

Payne, D., \& Joyner, B. E. (2006). Successful U.S. Entrepreneurs: Identifying Ethical Decision-making and Social Responsibility Behaviors. Journal of Business Ethics, 65(3), 203-217. doi:10.1007/s10551-005-4674-3

Powell, G. N., \& Eddleston, K. A. (2008). The paradox of the contented female business owner. Journal of Vocational Behavior, 73(1), 24-36. doi:10.1016/j.jvb.2007.12.005

Rau, R., Hoffmann, K., Metz, U., Richter, P. G., Rösler, U., \& Stephan, U. (2008). Gesundheitsrisiken bei Unternehmern. Zeitschrift für Arbeits- und Organisationspsychologie A\&O, 52(3), 115-125. doi:10.1026/0932-4089.52.3.115

Rauch, A., \& Frese, M. (2007). Let's put the person back into entrepreneurship research: A meta-analysis on the relationship between business owners' personality traits, business creation, and success. European Journal of Work and Organizational Psychology, 16(4), 353-385. doi:10.1080/13594320701595438

Razmus, W., \& Laguna, M. (2018). Dimensions of Entrepreneurial Success: A Multilevel Study on Stakeholders of Micro-Enterprises. Frontiers in Psychology, 9, 791. doi:10.3389/fpsyg.2018.00791

Reijonen, H., \& Komppula, R. (2007). Perception of success and its effect on small firm performance. Journal of Small Business and Enterprise Development, 14(4), 689-701. doi:doi:10.1108/14626000710832776

Renko, M. (2013). Early Challenges of Nascent Social Entrepreneurs. Entrepreneurship Theory and Practice, 37(5), 1045-1069. doi:10.1111/j.1540-6520.2012.00522.x

Reynolds, P. D. (1987). New Firms - Societal Contribution Versus Survival Potential. Journal of Business Venturing, 2(3), 231-246. doi:Doi 10.1016/0883-9026(87)900115

Richard, P. J., Devinney, T. M., Yip, G. S., \& Johnson, G. (2009). Measuring organizational performance: Towards methodological best practice. Journal of Management, 35(3), 718-804. doi:10.1177/0149206308330560

Robichaud, Y., McGraw, E., \& Roger, A. (2001). Toward the Development of a Measuring Instrument for Entrepreneurial Motivation. Journal of Developmental Entrepreneurship, 6(2), 189.

Sarasvathy, S. D., Menon, A. R., \& Kuechle, G. (2013). Failing firms and successful entrepreneurs: serial entrepreneurship as a temporal portfolio. Small Business Economics, 40(2), 417-434. doi:10.1007/s11187-011-9412-x

Schaarschmidt, U., \& Fischer, A. W. (2001). Bewältigungsmuster im Beruf Göttingen: Vandenhoeck \& Ruprecht.

Schulz, R., \& Heckhausen, J. (1996). A life span model of successful aging. American Psychologist, 51(7), 702-714. doi:10.1037/0003-066X.51.7.702

Schutjens, V. A., \& Wever, E. (2000). Determinants of new firm success. Papers in Regional Science, 79(2), 135-159.

Seelos, C., \& Mair, J. (2005). Social entrepreneurship: Creating new business models to serve the poor. Business Horizons, 48(3), 241-246. doi:10.1016/j.bushor.2004.11.006

Shaw, E., \& Carter, S. (2007). Social entrepreneurship. Journal of Small Business and Enterprise Development, 14(3), 418-434. doi:10.1108/14626000710773529 
St-Jean, E., \& Audet, J. (2012). The role of mentoring in the learning development of the novice entrepreneur. International Entrepreneurship and Management Journal, 8(1), 119-140. doi:10.1007/s11365-009-0130-7

Staniewski, M. W., \& Awruk, K. (2017). Questionnaire of entrepreneurial success - Report on the initial stage of method construction. Journal of Business Research. doi:10.1016/j.jbusres.2017.11.041

Stephan, U., Hart, M., \& Drews, C.-C. (2015). Understanding motivations for entrepreneurship: A review of recent research evidence.

Sternberg, R. J., \& Lubart, T. I. (1999). The concept of creativity: Prospects and paradigms. Handbook of creativity, 1, 3-15.

Sydler, R., Haefliger, S., \& Pruksa, R. (2014). Measuring intellectual capital with financial figures: Can we predict firm profitability? European Management Journal, 32(2), 244-259. doi:10.1016/j.emj.2013.01.008

Terjesen, S., Vinnicombe, S., \& Freeman, C. (2007). Attracting generation Y graduates. Career Development International, 12(6), 504-522. doi:10.1108/13620430710821994

Van de Ven, A. H., Sapienza, H. J., \& Villanueva, J. (2007). Entrepreneurial pursuits of selfand collective interests. Strategic Entrepreneurship Journal, 1(3-4), 353-370. doi: $10.1002 /$ sej.34

Van Praag, C. M., \& Versloot, P. H. (2007). What is the value of entrepreneurship? A review of recent research. Small Business Economics, 29(4), 351-382.

Vandello, J. A., Hettinger, V. E., Bosson, J. K., \& Siddiqi, J. (2013). When Equal Isn't Really Equal: The Masculine Dilemma of Seeking Work Flexibility. Journal of Social Issues, 69(2), 303-321. doi:10.1111/josi.12016

Wach, D., Stephan, U., \& Gorgievski, M. J. (2016). More than money: Developing an integrative multi-factorial measure of entrepreneurial success. International Small Business Journal, 34(8), 1098-1121. doi:10.1177/0266242615608469

Walker, E., \& Brown, A. (2004). What success factors are important to small business owners? International Small Business Journal, 22(6), 577-594.

York, J. G., \& Venkataraman, S. (2010). The entrepreneur-environment nexus: Uncertainty, innovation, and allocation. Journal of Business Venturing, 25(5), 449-463. doi:10.1016/j.jbusvent.2009.07.007

Zahra, S. A., \& Wright, M. (2011). Entrepreneurship's next act. Academy of Management Perspectives, 25(4), 67-83. doi:10.5465/amp.2010.0149

Zhou, J., \& George, J. M. (2001). When job dissatisfaction leads to creativity: Encouraging the expression of voice. Academy of Management Journal, 44(4), 682-696.

doi: $10.2307 / 3069410$ 